\section{LA FORMACIÓN DEL LAICADO}

Autor: Antonio Cartagena. Director del Secretariado de la Comisión Episcopal de Apostolado Seglar.
Nos ofrece Antonio Cartagena - Director del Secretariado de la Comisión Episcopal de Apostolado Seglar-una visión de la formación del laicado de hoy, asumiendo el importante reto que el llevarla a cabo con seriedad supone para la Iglesia desde el ahora para el futuro. Los caminos de santidad necesitan una pedagogía especifica, verdadera y propia. La formación, metodología y contenidos, ha de estar en consonancia con las exigencias de la misión del laico en la nueva evangelización.

DOI: https://doi.org/10.52039/seminarios.v47i159.988

\title{
Introducción
}

Atento a la llamada amable de la revista voy a tratar de explicar algo de la formación laical que diversos grupos, movimientos y asociaciones, tienen en cuenta en sus planes y programas de formación. La Formación de los Laicos es uno de los desafíos prioritarios y más importantes para la Iglesia, y en concreto, para las asociaciones de fieles y para las diócesis de la Iglesia en España.

La Comisión Episcopal de Apostolado Seglar (CEAS), ha realizado y realiza muchos esfuerzos para responder a estos desafíos, así hace cinco años elaboró la Guía-marco de Formación de Laicos, cuyo objetivo es poder servir a los Movimientos y asociaciones laicales de pautas de confrontación para una formación con objetivos, con un sentido, pues no cualquier formación logra, a nuestro parecer, la madurez adulta que nuestros fieles laicos necesitan. También es una oferta a nuestras

Acertar en la formación laical para lograr la madurez adulta 
diócesis para que la consideren en sus planes de formación diocesanos como un apoyo y orientación en esta tarea. Nuestra Iglesia, cada Iglesia particular, necesita de asociaciones y movimientos que se planteen una formación integral, permanente, realista, gradual y sistemática.

Además de este instrumento, podríamos decir, más especializado pero que comprende todas las etapas de la formación: iniciación, consolidación y maduración permanente de la identidad cristiana. La CEAS propone para las parroquias y gentes más sencillas o sin conciencia misionera un Cursillo para el Apostolado de los Laicos, dividido en tres partes: ¿Qué Iglesia tenemos, qué mundo nos toca vivir y qué laicos cristianos son necesarios en esta Iglesia y para evangelizar a este mundo? que se va impartiendo por diócesis y provincias eclesiásticas con buenos resultados.

Ciñéndome ahora a la Guía-marco de Formación de Laicos, ésta se dirige principalmente a los sacerdotes vocacionados ( ¿y quién puede eximirse de esta llamada?) y "preparados", a los responsables de formación de los movimientos y asociaciones de fieles, en definitiva a los formadores y a los formadores de formadores, aunque, evidentemente, puede ser utilizado por cualquier persona que quiera trabajar en este campo.

Guía marco orientada a pedagogía y estilo
La Guía-marco de Formación de Laicos requiere un gran esfuerzo de adaptación a cada uno de los ambientes. No desarrolla contenidos o temas de formación. Se orienta hacia determinadas sugerencias pedagógicas, metodológicas, de estilo, de "temporalización",... etc., que son la base para el desarrollo de los contenidos que el responsable de formación puede encontrar en los distintos planes de los movimientos y asociaciones, en otros libros, documentos y algún que otro Manual, pero confrontándolos siempre con los criterios que aquí se exponen.

Para esta formación nos congratula enormemente y asumimos las palabras de la Carta apostólica "Novo Millenio ineunte", que nos ha regalado el Papa Juan Pablo II, al finalizar el Año Jubilar: "Pero también es evidente que los caminos de la santidad son personales y exigen una "pedagogía de la santidad" verdadera y propia, que sea capaz de adaptarse a los ritmos de cada persona. Esta pedagogía debe enriquecer la propuesta dirigida a todos con las formas tradicionales de ayuda personal y de grupo, y con las formas más recientes ofrecidas en las asociaciones y en los movimientos reconocidos por la Iglesia" (31). 
$\mathrm{Y}$, contando absolutamente conque "no nos hagamos ilusiones: $\sin$ este camino espiritual -espiritualidad de comunión-, de poco servirían los instrumentos externos de comunión. Se convertirían en medios sin alma, máscaras de comunión más que sus modos de expresión y crecimiento" (43).

\section{LA FORMACIÓN DE LOS LAICOS}

\section{Importancia de la Formación}

Siempre, pero, quizás actualmente más, debemos ser sensibles y tomar conciencia sobre la importancia, urgencia y necesidad de una formación seria e integral de los fieles laicos. Así se considera en el documento: Los Cristianos Laicos, Iglesia en el Mundo de la Conferencia Episcopal Española que, en su cap. III, señala: La formación de los laicos es una prioridad de máxima urgencia para toda la Iglesia (70). Y, anteriormente el Santo Padre, Juan Pablo II, en la Exhortación Apostólica "Christifideles laici", indica esta necesidad, de manera especial en el último capítulo.

Formación y espiritualidad son dos temas que por su estrecha relación hay que tratarlos conjuntamente. Es indudable que las vivencias y las prácticas espirituales que personalmente realizamos, están de ordinario conectadas con el tipo de formación que como sujetos determinados hemos recibido; y viceversa, hablando de estos temas, el anhelo por afianzar y progresar en la propia formación, depende ordinariamente de la seriedad con que se asuman las propias obligaciones eclesiales, y en definitiva, con la intensidad de nuestra propia vida cristiana.

Juan Pablo II, en el discurso a los miembros de la Asociación Cristiana de Trabajadores Cristianos (ACLI), reunidos en la Plaza de san Pedro para celebrar el 50 aniversario de su fundación (1.5.95), insiste una vez más en la formación y dice:

"La plena aceptación del evangelio, tanto en la exigencia personal como en el compromiso asociativo y en la acción social dará fuerza y originalidad a vuestra presencia... Es necesario para este fin -la conversión al Evangelio- recuperar el compromiso por la formación... Objetivo de todo itinerario educativo, cristianamente motivado, es la maduración de una auténtica espiritualidad... Resultados de dicho

Formación y espiritualidad están interrelacionados 
esfuerzo formativo serán la formación integral de las personas, a través del crecimiento en una fe consciente y capaz de testimonio misionero, la adquisición de conocimientos y de competencias, la capacitación para el estudio, para el discernimiento, para las opciones responsables, para la proyección social, para la ciudadanía activa y solidaria, para la coherencia y para la entrega de sí por el bien común" (Ecclesia, núm.2.738/27.5.95. p.35 (795). Larga cita que no tiene desperdicio y que me he resistido a no citar literalmente.

\section{Comprensión de su significado}

Proceso largo, integral y peculiar

1.2.1. Se entiende como un proceso largo, complejo, en el que se integran múltiples elementos "formadores" con el fin de que se conviertan en imágenes vivas de Jesucristo, aquellos que han sido llamados y han aceptado su vocación, cualquiera que esta sea.

1.2.2. Hay que situarse en un tipo de formación que pretende ser "integral". Se dan dos aspectos distintos en la formación. Según el Código de Derecho Canónico, el primer aspecto es el derecho general de todos los fieles laicos a recibir los medios sobrenaturales de la formación cristiana -la Palabra y los Sacramentos - (c.213) y el derechodeber de todos los fieles cristianos de adquirir el conocimiento de la doctrina adecuado a la condición de cada uno (c.229 § 1 en correspondencia con el c.217).

1.2.3. Si el laico debe impregnar con su fe la realidad social que le circunda, lo peculiar de su formación no consistirá sin más en una peculiar formación doctrinal religiosa o espiritual. Dentro de la integridad de la formación de la persona, en el caso concreto del laico, junto a esas facetas, se sitúa en muy primer término la formación profesional, humana, cívica, etc.., que el fiel laico adquiere -como sus demás conciudadanos- en el trabajo, en el seno de la familia, en la vida de relación social, en la escuela o universidad, en la diversión, etc.

Todos esos no son elementos accesorios y secundarios, sino aspectos integrantes de una formación sin la cual el laico no estará en condiciones de llevar a cabo la función eclesial que le corresponde (GS, 43; AA, 7 y cap. III; y AA, 29).

1.2.4. Formar es ayudar, a quienes están en formación, a que progresivamente hagan suyos "los mismos sentimientos de Cristo Jesús" 
(Flp 2,5). Se trata, en suma, de entender la formación como un proceso de "renovación de espíritu y mentalidad", de "revestirse de humanidad" (Ef. 4, 12-24).

En resumen, entendida así la formación, queda claro que es mucho más que "in-formación" o aprendizaje de conocimientos de cualquier orden, por elevados que estos sean. Es "con-formación" en su sentido primario de dar forma; desde este punto de vista, tiene importantes elementos de socialización y de "probación", para los que no bastan profesores, libros y pupitres, sino que se hacen necesarias experiencias de vida, compañeros y formadores, acompañamiento. Y, desde ahí, se puede también decir que la formación es "con-formación", como proceso que, por su propia naturaleza, nunca puede ser solitario y ha de ser siempre comunitario, acompañado.

\section{OBJETIVOS DE LA FORMACIÓN DEL LAICO}

Proceso de renovación de espíritu y mentalidad

Formación

$=$ confor mación. Experiencia de vida y acompañamieno

Los objetivos son de varias clases:

1. El objetivo fundamental es descubrir cada vez más claramente la propia vocación y la disponibilidad siempre mayor para vivirla en el cumplimiento de la propia misión.

2. Y, objetivos complementarios son:

a) la formación para una presencia misionera en el mundo actual de tal manera que el laico viva simultáneamente su crecimiento en Cristo, su comunión eclesial y su inserción en el mundo.

b) la formación para una nueva evangelización que sea fiel a la Buena Noticia de Jesús y atenta a los fuertes desafíos de la sociedad y de la historia.

c) la formación para el testimonio, el compromiso, la profecía, apoyados en la oración, la fidelidad y la esperanza.

\section{CRITERIOS PARA LA FORMACIÓN DE LOS FIELES LAICOS}

a) Criterios eclesiales:

1) Formación integral: que integre el ser miembros de la Iglesia y de la sociedad humana, lo cual supone varias dimensiones de la formación: 
* Formación espiritual para crecer en la intimidad con Cristo, en la conformación con la voluntad del Padre y en la entrega generosa, en la caridad y la justicia, a los hermanos.

Formación integral: espiritual, doctrinal, humana, en comunión

* Formación doctrinal que permita dar razón de la esperanza y un conocimiento de la Doctrina Social de la Iglesia que respalde y anime el compromiso socio-político.

* Formación humana que lleve al crecimiento personal en los valores humanos, en la competencia profesional, en el sentido de la familia y en el sentido cívico, al igual que en aquellos valores (virtudes) relativos a las relaciones sociales como son la integridad, el espíritu de justicia, la sinceridad, la fortaleza de ánimo, etc.

2) Una formación que además de "saber" vaya dirigida al "hacer" y a capacitarse cada vez más en el proyecto personal y del movimiento o comunidad misionera.

3) Una formación por y en la Iglesia en una recíproca comunión y colaboración de todos sus miembros: sacerdotes, religiosos/as y fieles laicos.

4) La formación no es un derecho o privilegio de unos cuantos, sino un derecho y un deber de todos.

5) No se da formación verdadera y eficaz si cada uno no asume y desarrolla por sí mismo la responsabilidad de la formación, si cada uno no es protagonista de su propia formación, o sea, la autoformación como proceso de maduración y de crecimiento.

\section{b) Criterios pedagógicos:}

Con una pedagogía de diálogo, con metas claras y realistas
1) Partir siempre de las necesidades y aspiraciones de los formandos.

2) Tener en cuenta siempre su condición de persona, que a su nivel, condición y edad, toma decisiones y tiene sus responsabilidades. Que sea más en diálogo que como maestro-alumno

3) Aprovechar la experiencia del movimiento y del responsable de formación, del formado, del militante, del adulto responsable, y asegurar que los conocimientos que se comparten puedan articularse con su propia experiencia y con sus conocimientos anteriores.

4) Que se tengan metas claras, concretas, realistas, que no se impondrán sino que se dialogarán con los participantes en el grupo. 
5) Hay que mantener un nivel alto de motivación para poder asegurar la permanencia y el apoyo necesario para lograr que se pueda producir un cambio efectivo.

6) El ambiente del grupo debe desarrollarse con personas de características similares y complementarias.

7) El grupo tiene que ser acogedor y debe hacer sentir a cada uno de sus componentes, que se les aprecia y valora.

8) Hay que respetar los procesos y los ritmos de cada uno, sus cualidades y sus limitaciones, procurando emplear pedagogía y métodos activos que ayuden a una mayor comprensión y profundización de lo que se va experimentando.

9) Hay que seguir procesos que ayuden tanto a "aprender a ser" como a "aprender a aprender", con lo cual el grupo, la persona, descubre que la formación no es una sola etapa, sino que es un proceso de formación permanente, y por esta razón se mantiene ahí.

\section{CONTENIDOS DEL OBJETIVO FUNDAMENTAL DE LA FORMACIÓN LAICAL}

“...entra en las almas santas, para hacer de ellas amigos de Dios y profetas. Porque Dios ama únicamente a los que conviven con la Sabiduría" (Sab 7,27-28).

\section{1. iAmigos de Dios y profetas!}

Esa es la meta de la formación: hombres y mujeres cristianos fuertemente comprometidos con la realidad temporal desde el corazón de la Iglesia y siempre dispuestos a dar razón de la esperanza que hay en nosotros (cf. 1 Pd 3,15). Lo cual supone un progresivo crecimiento en nosotros de Cristo, nuestra vida, enviado por el Padre para anunciar la Buena Noticia del Reino a los pobres. El fin, el término siempre nuevo y siempre inacabado, de nuestra formación, es Cristo: "hasta que se forme Cristo en vosotros" (Gal 4,19). Lo cual ocurrirá en plenitud cuando él se manifieste (cf. Col, 3,4) y entonces "seremos semejantes a él, porque le veremos tal cual es” (1 Jn 3,2).

Lo anterior no significa una formación irrealista y desencarnada. Es volver al núcleo mismo, al centro, de nuestro camino cristiano. Los

Hacer amigos de Dios y profetas. El núcleo: Cristo 
laicos cristianos, y todos los cristifideles, la respuesta que hemos de dar a los retos actuales, siempre debe y tenemos que darla desde el Evangelio.

Pero un Evangelio meditado y contemplado, vivido y compartido, experimentalmente anunciado con la fuerza del Espíritu y realizado todos los días en las condiciones comunes de nuestra vida ordinaria.

En este sentido y, siguiendo con los objetivos complementarios, vamos a hacer algunas consideraciones sobre la formación.

\subsection{Formación para una presencia misionera en el mundo actual}

"Como el Padre me envió, también yo os envío" (Jn 20,21)

"Como tú me has enviado al mundo, yo también los he enviado al mundo" (Jn 17,18)

Como respuesta al envío. Ser presencia en el mundo
4.2.1. Es toda la Iglesia la que, revestida del Espíritu del testimonio y de la profecía, es enviada al mundo para ser allí "sacramento universal de salvación".

Dos grandes textos del Concilio Vaticano II, conectados entre sí, nos revelan y explican el sentido de esta expresión clave en la Eclesiología del Concilio: la Iglesia como "sacramento universal de salvación".

El primero es de la Lumen Gentium, cuando nos habla de la escatología: "Cristo, levantado sobre la tierra, atrajo hacia sí a todos, habiendo resucitado de entre los muertos, envió sobre los discípulos a su Espíritu vivificador, y por Él a su Cuerpo, que es la Iglesia, 'sacramento universal de salvación" (LG 48). Para la Guía-marco de Formación de Laicos y para cualquier proyecto de formación interesa subrayar que la expresión "sacramento universal de salvación" se relaciona con tres realidades fundamentales:

$1^{\text {a }}$ - La renovación definitiva en Cristo ("los cielos nuevos y la tierra nueva donde habitará la justicia"; dimensión escatológica de la Iglesia misionera y peregrina que ya se va realizando en la historia y que alcanzará su plenitud en la eternidad).

Es toda la exigencia de "la nueva creación en Cristo" $(2$ Cor 5,17$)$ que está en la base de todo auténtico proyecto de formación: despojarse del "hombre viejo" para revestirse del "Hombre Nuevo, creado según Dios, en la justicia y santidad de la verdad" (Ef 4,24; cf. Col 
3,9). La formación es un continuo proceso de conversión que nos lleva a esperar y a vivir cotidianamente "la novedad pascual".

$2^{a}$. - El Misterio Pascual de Jesús (muerte y resurrección, ascensión a los cielos y pentecostés) como centro de nuestra vida y de nuestra acción, como punto esencial de referencia para nuestra formación.

En definitiva, formar testigos y profetas, cristianos comprometidos en el mundo desde el Evangelio, es prepararlos para gustar la cruz y el martirio, para hacerlos solidarios con los que sufren, para gritar al mundo "la esperanza que nunca falla" (cf. Rom 5,5). Desde el Misterio Pascual de Jesús se adquiere mayor capacidad evangélica para descubrir los problemas, los conflictos, el drama del mundo y asumir el dolor y la esperanza de los pobres.

3a. - La Iglesia como Cuerpo, animada por el Espíritu de vida y constituida por él como comunidad misionera. La Iglesia no es plenamente sacramento universal de salvación, si no es ante toda verdadera comunión en el Espíritu. La Guía-marco, como todo proyecto de formación que se precie de verdadero, tiene presente ante todo la comunión con la Iglesia.

No es suficiente formar personas, o personalidades brillantes, pero individuales; hay que formar hombres y mujeres, chicos y chicas, niños y niñas, capaces de comunión (con el Ministerio Pastoral, con los religiosos/as, con los laicos, con todos los Movimientos y Asociaciones).

Formar para la comunión es formar en la pobreza, en la sencillez, en la capacidad de diálogo y de servicio, en un amor sincero y concreto por la Iglesia ( en el ámbito universal, a nivel interdiocesano y en el ámbito local). Formar para la comunión es necesariamente formar para el sufrimiento y la cruz.

El segundo texto a tener en cuenta y que nos ilumina el sentido de la expresión "sacramento universal de salvación" se encuentra en Gaudium et Spes cuando el Concilio concluye, a la luz de Cristo, Alfa y Omega, la fecunda interrelación entre la Iglesia y el mundo: “Todo el bien que el Pueblo de Dios puede dar a la familia humana al tiempo de su peregrinación en la tierra, deriva del hecho de que la Iglesia es "sacramento universal de salvación, que manifiesta y al mismo tiempo realiza el misterio del amor de Dios al hombre” (GS 45).

Conviene subrayar para el tema de la formación lo siguiente: toda la fecundidad de nuestra presencia en el mundo como testigos del resu-

El Misterio

Pascual, da mayor capacidad evangélica para descubrir los problemas del mundo

Con capacidad de comunión, en sencillez. $y$ abierto al diálodo

al


60

Toda eficacia depende de la manifestación del amor de Dios al hombre

citado, nuestra capacidad de cambiar desde dentro las estructuras de injusticia, depende de nuestra capacidad, como Iglesia, de manifestar claramente y de comunicar eficazmente el misterio del amor de Dios al hombre. Lo cual significa formar "testigos del amor": hombres y mujeres que tengan una honda experiencia del amor de Dios, que estén dispuestos a vivir en "la sinceridad del amor" y que griten a los hombres que la única forma de cambiar el mundo -hacerlo más fraterno y humano- es vivir con fidelidad cotidiana las bienaventuranzas evangélicas.

Cuando se habla de la formación para una presencia misionera en el mundo de hoy, hay que insistir en lo siguiente:

Que, aunque toda la Iglesia tiene que hacerse y estar presente en el mundo, es particularmente el laico el que vive una providencial experiencia eclesial de presencia secular y de tarea temporal. Con todo lo que tiene de alegría y de sufrimiento, de pecado y santidad.

Por tanto hay que formar al laico para que viva simultáneamente su crecimiento en Cristo, su comunión eclesial y su inserción en el mundo.

No basta con formar apóstoles que vayan generosamente al mundo; hay que formar, desde las difíciles y dramáticas condiciones del mundo, cristianos que vayan creciendo en Cristo y edificando la Iglesia. Todo el tema de la espiritualidad está aquí.

De aquí la necesidad y urgencia de una formación "en la Iglesia y para el mundo". Formación para la unidad interior frente a dos realidades distintas pero no separables (Iglesia-Mundo): el laico vive la Iglesia desde la dimensión temporal del Reino. Exige una comprensión

Comprensión del Misterio. Contemplación de la realidadmundo muy grande del Misterio de Cristo en la Iglesia; pero, al mismo tiempo, una gran capacidad contemplativa para descubrir y asumir "el pecado del mundo" en el sufrimiento de los hombres.

Formar al laico para ser presencia cristiana y eclesial en el mundo exige una doble dimensión: capacidad para no huir del mundo refugiándose exclusivamente en la comunidad eclesial (especie de "clericalismo"), capacidad para no vaciar su fe en Cristo y su Evangelio, su identidad eclesial y su vocación esencial de ser testigo del Resucitado (especie de "secularismo").

Lo anterior nos lleva a una última consideración cargada de esperanza. Hay que formar al laico, consciente de su misión providencial como miembro activo del Pueblo de Dios, a mirar al mundo con la mirada redentora de Jesús: “Así amó Dios al mundo que le dio a su 
Hijo unigénito... no para condenar al mundo sino para que el mundo sea salvo por él" (cf. Jn 3,16-17). Esto exige en el laico una triple mirada sobre el mundo:

- un mundo que ha sido herido por el pecado,

- un mundo que ha sido ya redimido en esperanza,

- un mundo que se ofrece al laico como espacio providencial donde él puede realizar su santidad, vivir su vocación de Iglesia y construir con todos los hombres de buena voluntad la nueva civilización del amor, de la verdad.

\subsection{Formación para una nueva evangelización}

"El Espíritu del Señor está sobre mí, porque me ha ungido. Me ha enviado a anunciar a los pobres la Buena Nueva, y a proclamar la liberación a los cautivos y la vista a los ciegos, para dar la libertad a los oprimidos y proclamar un año de gracia del Señor" (Lc 4, 18-19).

El Señor nos ha hecho a todos testigos de su resurrección. El Señor nos ha dicho a todos: "Id y evangelizar". (La evangelización no es privilegio de unos pocos -sacerdotes, religiosas/os- sino obligación de todos. Todo el pueblo de Dios es profético; de aquí la responsabilidad y el compromiso evangelizador del laico: "Ay de mí si no anunciara el Evangelio").

El mundo de hoy presenta nuevos desafíos a nuestra evangelización; una sociedad particularmente secularizada, problemas nuevos que plantea el progreso científico-técnico, la globalización económica y de las comunicaciones, el individualismo, ¿hambre y sed en el mundo de la Palabra de Dios?. Más que nunca se nos hace urgente la llamada del Señor a una nueva evangelización.

Formar para una nueva evangelización supone lo siguiente:

a) Penetrar contemplativamente la Palabra de Dios. Se trata de un anuncio explícito de Jesús y su Evangelio. Supone encontrarse con Cristo, entrar en su Persona, asumirla, experimentarla. Luego "predicar a Cristo y Cristo crucificado".

Centrar el Mensaje en la Pascua de Jesús. Corremos el riesgo de quedarnos en el puro análisis de los problemas, a lo sumo compartir- 
Propio de la Iglesia: no el análisis de problemas, sino el anuncio de la Buena Noticia los, pero sin darles una iluminación evangélica desde Cristo, sin redimirlos.

El mundo tiene derecho a nuestra presencia evangelizadora. Lo propio de la Iglesia -lo específico del laico inmerso por vocación en el mundo- es el anuncio profético de la Buena Noticia de Jesús con todas sus exigencias de justicia, amor, de paz; es válido para todos lo que San Pablo escribe de sí mismo: "ser para los gentiles ministro de Cristo Jesús, ejerciendo el sagrado oficio del Evangelio de Dios, para que la oblación de los gentiles sea agradable, santificada por el Espíritu Santo" (Rom 15,16).

No se trata de convertirnos en intelectuales de la Palabra, pero es urgente una continua interiorización en la Palabra de Dios, hecha con corazón pobre y contemplativo: "te doy gracias, Padre,... porque has ocultado estas cosas a los sabios y prudentes, y se las has revelado a los pequeños" (Mt 11,25).

b) Estar a la escucha de los signos de los tiempos, de los nuevos desafíos que se presentan a nuestra evangelización en el campo de la ciencia y de la técnica, de la cultura y del trabajo, de la promoción humana y de las relaciones internacionales.

¿Qué significa hoy ser enviados a evangelizar a los pobres? ¿Quiénes son los pobres? ¿Cómo abrirles la riqueza esperanzadora y consoladora de la Buena Noticia de Jesús? ¿Cuáles son en nosotros las exigencias radicales de una Palabra acogida y comunicada desde nuestra condición secular?

c) Preparar testigos y profetas. El mundo ya no cree simplemente a los maestros, exige testigos. Una nueva evangelización supone hombres y mujeres profundos, coherentes, fuertes, capaces de sufrimiento. Hombres y mujeres revestidos fuertemente por el Espíritu Santo, con una gran capacidad contemplativa, pero profundamente insertados en el mundo de las realidades temporales. Hombres y mujeres que anuncien como Jesús, que el Reino de Dios ha llegado, que es preciso convertirse y creer en la Buena Noticia (cf. Mc 1,15).

\subsection{Formación para ser testigos y profetas}

"Vosotros seréis mis testigos" (Hch 1,8)

"Yo te haré profeta de las naciones" (Jer 1,5) 
Vivimos tiempos particularmente difíciles pero llenos de esperanza. Se nos pide realismo y que sepamos asumir el dolor de los hombres. Para ello nos hace falta una fuerte capacidad contemplativa. ;Ser testigos de la resurrección de Jesús y profetas de la esperanza! Pues el mundo está lleno de "profetas de calamidades".

Pero un profeta no se improvisa: hace falta mucha pobreza, mucha oración, mucho coraje. Un profeta es siempre un hombre que se ha dejado invadir por la potencia del Espíritu y anuncia en nombre de Jesús las maravillas de Dios. Hay que crear en la Iglesia, en nuestras comunidades cristianas, en nuestros movimientos y asociaciones, un clima tal que pueda el Espíritu de Dios suscitar profetas "Yo derramaré mi Espíritu en toda carne. Vuestros hijos y vuestras hijas profetizarán" (J1 3,1). Hemos sido hechos por el bautismo miembros activos de un pueblo profético. No apaguemos el Espíritu (cf. 1 Tes 5,19).

¿Cómo formar para el testimonio y la profecía? Formar para la oración, para la fidelidad, para la esperanza.

Para la oración: "amigos de Dios y profetas". Hace falta una oración profunda, serena, contemplativa. No vivimos en el desierto, pero el desierto tiene que instalarse en nuestro corazón. Oración continua basada en la Palabra de Dios y en los Sacramentos (Reconciliación Eucaristía). Una nueva evangelización exige siempre la experiencia del testigo: "Lo que existía desde el principio, lo que hemos oído, lo que hemos visto con nuestros ojos, lo que contemplamos y tocaron nuestras manos acerca de la Palabra de vida, pues la Vida se manifestó, y nosotros la hemos visto y damos testimonio y os anunciamos la vida eterna,... lo que hemos visto y oído, os lo anunciamos" (Jn 1,1-3). Oración hecha desde "las condiciones ordinarias de la vida familiar y social" (LG 31).

Para la fidelidad. La profecía exige fidelidad al Espíritu. No inventamos nosotros la profecía, simplemente la comunicamos: "adondequiera que yo te envíe irás, y todo lo que te mande dirás... Mira que he puesto mis palabras en tu boca. (Jer 1,7-9).

Por eso no podemos eludir la profecía, por pereza, por miedo. La profecía exige el coraje del Espíritu: para anunciar y para denunciar, para anunciar totalmente a Jesús y para denunciar cualquier tipo de injusticia y de pecado.

La profecía exige el coraje del Espíritu
Ser profetas: invadidos por la presencia de Dios

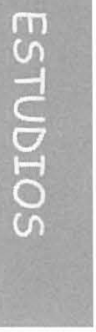


Para la esperanza: sin dejar de ser realistas ni de asumir evangélicamente el sufrimiento de los otros, saber descubrir la maravillosa fecundidad del Misterio Pascual de Jesús.

\section{CONCLUSIÓN}

En consecuencia a) se necesita un laicado con sentido eclesial. La correcta promoción de los laicos, además de suscitar, orientar y acompañar su espiritualidad y su formación, ha de atender a la plena inserción del laico en la vida de la Iglesia en orden a su edificación y renovación constantes.

Que los

laicos

tomen conciencia de que son Iglesia
Laico activo eficaz en la vida social y política
La nueva formación ha de tener como uno de sus objetivos fundamentales el lograr que los fieles laicos adquieran una conciencia plena de que son Iglesia. Y, como fruto de esa conciencia, su entrega libre a la Iglesia, para comprometerse plenamente, según su propio carisma, con el fin apostólico que la caracteriza: evangelizar y salvar a los hombres y animar el orden temporal con el espíritu evangélico.

Aparece así la importancia y actualidad de la problemática eclesial, que sólo puede resolverse a través de un profundo diálogo entre los pastores y los fieles. Todos tenemos experiencia de lo difícil que resulta encontrar el punto exacto de equilibrio que salve, simultáneamente, a) la comunión eclesial clara y contundentemente afirmada, vivida sin ningún adjetivo restrictivo y sin ningún "pero" matizador; y b) el respeto profundo a la nueva conciencia seglar, amante de su autonomía y libertad, pero deseosa de contribuir a mejorar, con su crítica y con su esfuerzo, el rostro de una Iglesia que el hombre de hoy frecuentemente rechaza

$\mathrm{Y}, \mathrm{b})$ Se necesita un laicado activo y eficaz en la vida social y política. La tarea del laicado no se reduce a ser fermento de vida, renovación y comunión eclesial, sino muy especialmente, fermento de la transformación cristiana del mundo.

La Iglesia cumple esta misión, en primer lugar, preparando laicos bien formados y alentando su compromiso cristiano en la sociedad para que ésta sea, cada vez más, una analogía lo más perfecta posible del Reino de Dios. Pero la misma Iglesia, ha de estar comprometida como tal en la sociedad, siendo con el ejemplo de su vida, impulso y levadura para la realización progresiva del Reino de Dios. 
La misión evangelizadora de la Iglesia sitúa su compromiso en la sociedad en un plano diverso al de las demás realidades sociales y políticas. Tal plano de acción, cuya identidad y motivación son específicamente religiosas, está lleno de implicaciones sociales y políticas. Los cristianos han de ser unánimes en afrontar las implicaciones sociales y políticas de la fe, si bien las mediaciones a través de las cuales tales implicaciones se llevan a la práctica puedan, e incluso deban, ser diversas.

Actualmente, cuando los cristianos y la Iglesia encuentran tantas dificultades para estar presentes en la vida pública desde su identidad y misión específicamente religiosas, sería necesario un proyecto histórico como medio adecuado para poner de manifiesto, sin añorar confesionalismos trasnochados, la dimensión social y pública de la fe, mediante la cual ésta debe aparecer como lo que en verdad es: salvación plena del hombre y de la sociedad.

En resumen, para quienes desean formarse cristianamente, la imagen es Cristo, el hombre perfecto. ¿Qué tipo de persona queremos ser? ¿Qué tipo de cristiano laico queremos formar?

Cada uno tiene un estilo peculiar de vivir el evangelio, de seguir a Jesucristo. Él es el punto de llegada, con él hay que encontrarse íntimamente en el desarrollo de este ideal es necesario plantear objetivos, como se ha visto, pues es la forma correcta de lograrlo; ver la propia capacidad y la voluntad de alcanzarlo.

De la misma forma el modelo formativo y el método de formación son un medio a través del cual los laicos cristianos logran una intensa identificación espiritual y un compromiso de servicio; así afianzan su ideal, lo que debemos y queremos ser, para hacerlo permanente y firme. 